\title{
MHD NON-DARCIAN FLOW DUE TO HORIZONTAL STRETCHING SHEET EMBEDDED IN A POROUS MEDIUM WITH THERMAL STRATIFICATION EFFECTS
}

\author{
A. Banshiwal* and M. Goyal
}

Dept. of Mathematics, University of Rajasthan, Jaipur, India

*E-mail: anub671@gmail.com

Abstract:

The aim of present study is to analyze the non-Darcian effects on unsteady non-linear MHD flow of an incompressible, electrically conducting and viscous fluid over a horizontal stretching sheet embedded in a porous medium with heat source, viscous dissipation and thermal stratification. The dimensionless governing equations have been solved numerically by using 4th order Runge - Kutta method with shooting technique. The effects of pertinent parameters on velocity and temperature are depicted graphically and discussed in details.

Keywords: Viscous dissipation, thermal stratification, heat source, Runge-Kutta method, non-Darcy flow.

\begin{tabular}{llll} 
NOMENCLATURE & $C_{f}$ & Skin friction coefficient \\
$u, v$ & velocity components & $N u$ & Nusselt number \\
$f, f^{\prime}$ & dimensionless velocity components & $k_{1}$ & Porous parameter \\
$B_{0}$ & Magnetic field intensity & $U$ & Dimension less free stream velocity \\
$k$ & Permeability of medium & Greek symbols \\
$c_{f}$ & Form or drag coefficient & $v$ & kinematic viscosity \\
$Q^{\prime}$ & Rate of heat generation/absorption & $\sigma$ & Electric conductivity \\
$C_{p}$ & Specific heat & $\rho$ & Density \\
$a, n$ & Stretching rate and constant & $\eta$ & Similarity variable \\
$\operatorname{Re}_{x}$ & Reynolds number & $\mu$ & Dynamic viscosity \\
$\mathrm{Pr}^{\prime}$ & Prandtl number & $\alpha$ & Thermal conductivity \\
$M$ & Magnetic parameter & $\theta$ & Dimensionless temperature \\
$q_{w}$ & Heat transfer from sheet & $\psi$ & Stream function \\
$E c$ & Eckert number & \multicolumn{2}{|}{} \\
$F_{s}$ & Local inertia coefficient & Subscript \\
$T$ & temperature & $w$ & Wall \\
$x, y$ & directional coordinate along and normal the & $\infty$ & Free stream
\end{tabular}

\section{Introduction}

During the last decade fluid flow in porous media has an important bearing in many areas of reservoir engineering, such as petroleum, environmental and groundwater hydrology. Darcy' law also describes the phenomena of fluid flow in porous medium which is valid in a limited range of low velocities but at the high flow rate, inertia effect and turbulence become important and cause non Darcian flow. This type of flow in pours medium has many practical applications such as filtration, transpiration cooling, geothermal and biomechanical process. Many attempts have been made to study the non Darcian flow. Singh et al. (2011) studied the non-Darcian effects on natural convection flow in a vertical channel partially filled with porous 1813-8535 (Print), 2070-8998 (Online) @ 2018 ANAME Publication. All rights reserved. Received on: Sept., 2016 
medium. Taklifi et al. (2012) investigated non-Darcian flow through a non-isothermal vertical surface embedded in a porous medium. A study of Variable Fluid Viscosity of non-Darcian flow over a moving vertical plate in a porous medium with suction and viscous dissipation is carried out by Animasaun et al. (2014) and an analysis by Pal and Mondal $(2010,2011)$ made to study the effects of variable viscosity, Soret-Dufour, chemical reaction and thermal radiation on MHD non-Darcy unsteady mixed convective heat and mass transfer over a stretching sheet. Singh et al. (2011) dealt with Darcy-Brinkman-Forchheimer extended model with heat generation/absorption. Finite element analysis of hydromagnetic flow and heat transfer of a heat generation fluid over a surface embedded in a non-Darcian porous medium in the presence of chemical reaction was studied by Mohamed et al. (2009). Santhosh et al. (2009) analyzed non-Darcy models for mixed convection in a porous cavity using a multigrid approach and similar model was used by Hooman et al. (2008) to discuss about the effects of temperature-dependent viscosity on Be'nard convection in a porous medium.

Stratified fluids are found everywhere in nature. There are many examples of stratified fluids including thermal stratification of reservoirs and oceans, salinity stratification rivers, groundwater reservoirs, and oceans, heterogeneous mixtures in industrial, food, and manufacturing processing, density stratification of the atmosphere.

Basically the term stratification is related with the variation in the density field and density differences causes due to temperature and pressure differences. Thermal stratification effects on nonlinear hydromagnetic flow over a vertical stretching surface with a power-law velocity was studied by Kandasamy et al. (2007) and effects of thermal stratification on flow and heat transfer past a porous vertical stretching surface presented by Mukhopadhyay et al. (2012). Although the effect of stratification of the medium in a porous medium is important, very little work has been reported in the literature. Saha et al. (2004) considered the thermally stratified media for natural convection flow with combined buoyancy effects. Madhu et al. (2015) discussed the effects of viscous dissipation and thermal stratification on chemical reacting fluid flow over a vertical stretching surface with heat source.

The present study is an analysis on MHD flow using Darcy Forchheimer model with thermal stratification over a stretching sheet. Some similarity transformations are used to solve the governing equations by $4^{\text {th }}$ order Runge - Kutta integration method with shooting technique and the effects of various parameters such as Eckert number, magnetic field parameter, Grashof number, thermal stratification parameter, porous parameter and inertia parameter are shown in figures and analyzed in detail.

\section{Mathematical Formulation}

Considered a two dimensional incompressible fluid flow over a stretching sheet embedded in porous medium where the $x$ axis taken in the direction of flow along stretching sheet and $y$ axis is normal to it. A magnetic field of strength $B_{0}$ is applied transversely to the $x$ axis and the induced magnetic field due to motion of electrically conducting fluid is negligible. It is assumed that sheet is stretched with velocity $U(x)=a x$. Moreover, the sheet is maintained at the temperature $T_{w}$ and $T_{\infty}$ is the temperature of ambient fluid. Under the above stated physical situation the governing equations of continuity and energy under the Darcy-Forchheimer model are:

$$
\begin{aligned}
& \frac{\partial u}{\partial x}+\frac{\partial u}{\partial y}=0 \\
& u \frac{\partial u}{\partial x}+v \frac{\partial u}{\partial y}=v \frac{\partial^{2} u}{\partial y^{2}}-\frac{\sigma B_{0}^{2} u}{\rho}-\frac{v}{k} u-\frac{c_{f}}{\sqrt{k}} u^{2} \\
& u \frac{\partial T}{\partial x}+v \frac{\partial T}{\partial y}=\alpha \frac{\partial^{2} u}{\partial y^{2}}+\frac{Q^{\prime}}{\rho C_{p}}\left(T-T_{\infty}\right)+\frac{\mu}{\rho C_{p}}\left(\frac{\partial u}{\partial y}\right)^{2}
\end{aligned}
$$

where $u$ and $v$ are velocity component in $x$ and $y$ directions respectively, $v$ is the kinematic viscosity, $\sigma$ is 


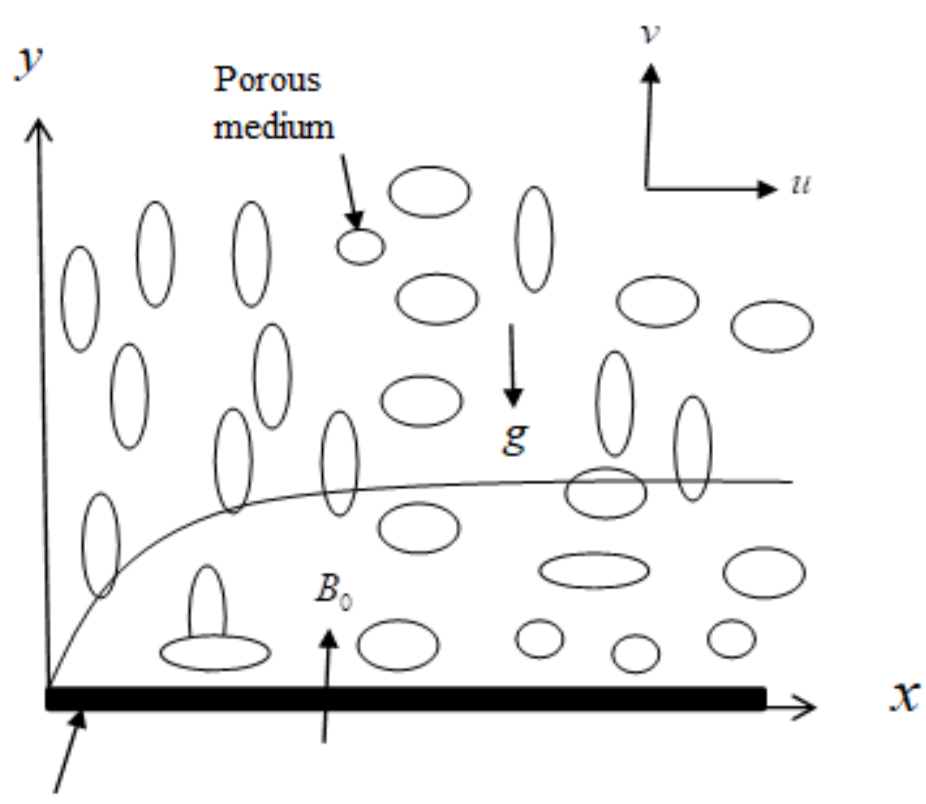

\section{Horizontal stretching sheet}

Fig. 1: Physical model for mathematical formulation

the electric conductivity, $\rho$ is the density of the fluid, $k$ is the permeability of the medium, $c_{f}$ is the form of drag coefficient, which is independent of viscosity and other physical properties of the fluid, $\alpha$ is the thermal conductivity of porous medium, $Q^{\prime}$ is the rate of heat generation/absorption, $\mu$ is the dynamic viscosity and $C_{p}$ is the specific heat at constant pressure. The flow is subjected to the following boundary conditions

$$
\begin{aligned}
& u=U(x)=a x, \quad v=0, \quad T=T_{w}(x) \quad \text { at } \quad y=0 \\
& u=0, \quad T=T_{\infty}(x)=(1-n) T_{0}+n T_{w}(x) \quad \text { at } \quad y \rightarrow \infty
\end{aligned}
$$

where $a$ is constant called stretching rate and $n$ is a constant such that $0 \leq n \leq 1$. The $n$ defined as thermal stratification parameter is equal to $\frac{m_{1}}{m_{1}+1}$ (Nakayama et al.,1989), where $m_{1}$ is a constant.

To solve the governing equation (see Acharya et al., 1999) similarity transformations are used,

$$
\begin{aligned}
& \psi=(v x U(x))^{1 / 2} f(\eta) \\
& \eta=(U(x) / v x)^{1 / 2} y
\end{aligned}
$$

The velocity components are given by

$$
u=\frac{\partial \psi}{\partial y}, v=-\frac{\partial \psi}{\partial x}
$$

The dimensionless parameters are defined as follows:

$$
\theta(\eta)=\frac{T-T_{\infty}}{T_{w}-T_{\infty}}
$$


$\operatorname{Re}_{x}=\frac{U x}{v}$ Reynolds number

$\operatorname{Pr}=\frac{\mu C_{p}}{k}=\frac{v}{\alpha}$ Prandtl number

$M=\frac{\sigma B_{0}^{2}}{\rho a}$ Magnetic parameter

$Q=\frac{Q^{\prime}}{\rho C_{p} a}$ Heat generation/absorption parameter

$E c=\frac{U^{2}}{C_{p}\left(T_{w}-T_{\infty}\right)}$ Eckert number

$k_{1}=\frac{v}{k a}$ Porous parameter

$F s=\frac{c_{f}}{\sqrt{k}} x$ Local inertia parameter

The wall shear stress $\tau_{w}$, may be expressed in terms of the local skin friction coefficient, $C_{f}$ as

$$
C_{f}\left(\operatorname{Re}_{x}\right)^{1 / 2}=f^{\prime \prime}(0)
$$

The local Nusselt number which are defined as

$$
N u=\frac{x q_{w}}{k\left(T_{w}-T_{\infty}\right)}
$$

where $q_{w}$ is the heat transfer from the sheet is given by

$$
q_{w}=-k\left(\frac{\partial T}{\partial y}\right)_{y=0}
$$

Using the non-dimensional variables, we get from Equations (16) and (17) as

$$
N u / \operatorname{Re}_{x}^{1 / 2}=-\theta^{\prime}(0)
$$

Also temperature variation of the surface is considered $T_{w}-T_{\infty}=N x^{n}$ and Equations (2)-(3) are transformed to

$$
\begin{aligned}
& f^{\prime \prime \prime}+f f^{\prime \prime}-\left(f^{\prime}\right)^{2}-\left(M+k_{1}\right) f^{\prime}-F s\left(f^{\prime}\right)^{2}=0 \\
& \theta^{\prime \prime}-\operatorname{Pr} n f^{\prime}\left[\theta+\frac{n}{1-n}\right]+f \operatorname{Pr} \theta^{\prime}+Q \operatorname{Pr} \theta+\operatorname{Pr} E c\left(f^{\prime \prime}\right)^{2}=0
\end{aligned}
$$

The boundary conditions (4) become

$$
\begin{aligned}
& f(0)=0, f^{\prime}(0)=1, \theta(0)=1, \\
& f^{\prime}(\infty)=0 \quad \theta(\infty)=0
\end{aligned}
$$




\section{Results and Discussions}

The transformed governing equations (19)-(20) with boundary conditions (21) are integrated by using the $4^{\text {th }}$ order Runge - Kutta method with shooting technique on MATLAB R2007b (7.5.0.342)(32 bit). In a shooting method the boundary value problem first converted into initial value problem, the missing terms in initial condition, $f^{\prime \prime}(0)$ and $\theta^{\prime}(0)$ are assumed and taking initial guesses for $f^{\prime \prime}(0)$ and $\theta^{\prime}(0)$ until the boundary conditions at infinite are satisfied. We select the appropriate finite value $\eta_{\infty}=8$ which depending upon the physical parameters.

The influence of the various physical parameters are shown graphically in Fig. 2 - Fig. 13 by considering $E c=0.01, M=0.5, \operatorname{Pr}=0.7, F s=0.1, n=0.1, k_{1}=0.5$, and $Q=-0.5$.

Figs. 2 - 3 illustrate the effects of magnetic parameter $M$ on velocity and temperature profiles. It is clear in Fig. 2 that if magnetic field parameter increases, the fluid velocity $f^{\prime}(\eta)$ decreases and also clear in Fig. 3 that the temperature $\theta(\eta)$ increases with an increasing of magnetic field parameter. As $M$ increases, the retarding force, which resists the flow, also increases and resultant there is a deceleration in velocity and increment in temperature.

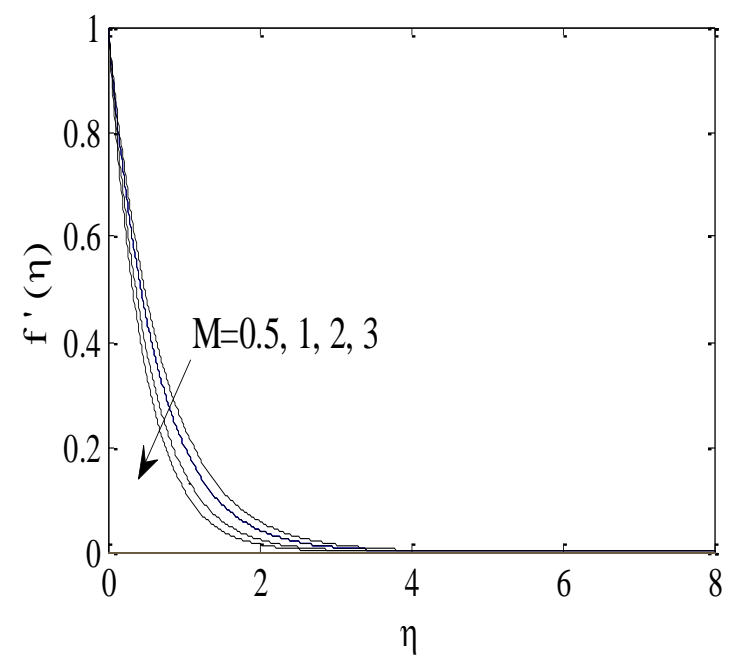

Fig. 2: Velocity profile for different values of $M$

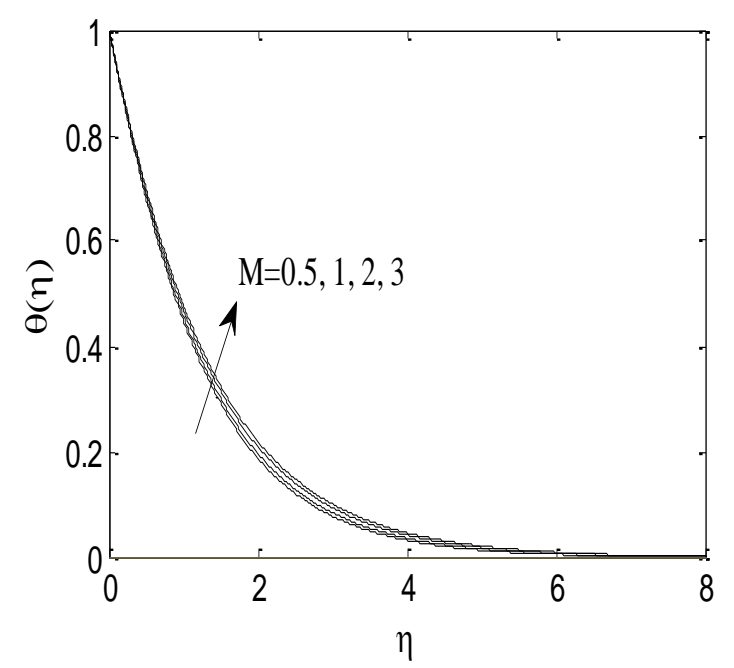

Fig. 3: Temperature profile for different values of $M$

The influence of inertia parameter $F S$ on the velocity and temperature are plotted in Figs. 4- 6. It is obvious that fluid normal $f(\eta)$ and axial velocity $f^{\prime}(\eta)$ decrease with an increasing of inertia parameter but temperature $\theta(\eta)$ is increasing and the increment is very small. As inertia parameter increases the resistance of the flow increases, causing the fluid flow in porous medium slow down and the temperature increases.

Figs. 7-9 show the effect of the porous parameter $k_{1}$ on fluid normal velocity $f(\eta)$, velocity $f^{\prime}(\eta)$ and temperature $\theta(\eta)$. It is clear from Figs. 7 and 8 that the fluid velocity $f(\eta)$ and $f^{\prime}(\eta)$ decrease with an increase in porous parameter also it appears in Fig.9 that the temperature increases with an increasing of porous parameter. The increase in porous parameter of the fluid is due to enhancement of viscosity of the fluid or decrease in permeability of porous medium. This will result a reduction in velocity of fluid and enhancement in temperature. 


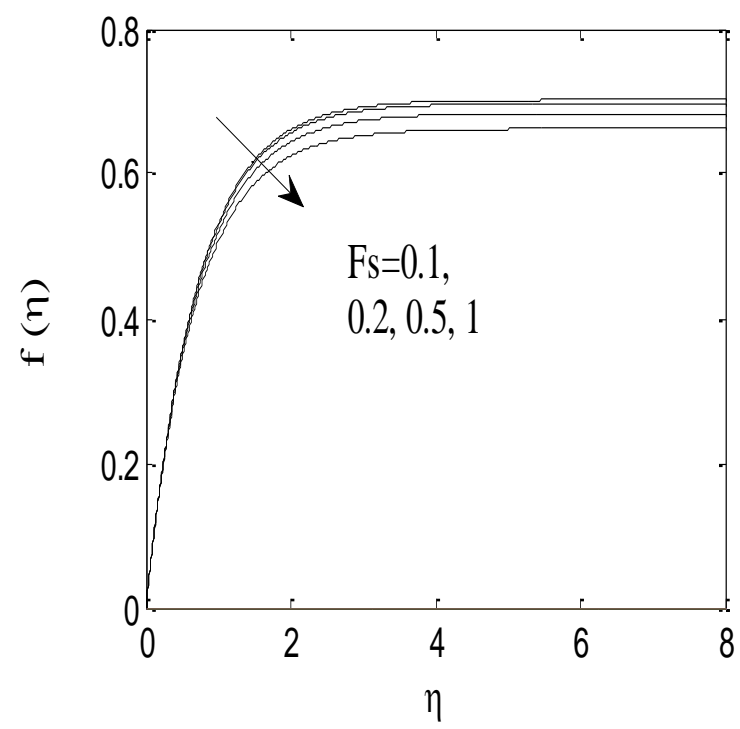

Fig. 4: Normal velocity $f(\eta)$ profile for different values of $F S$

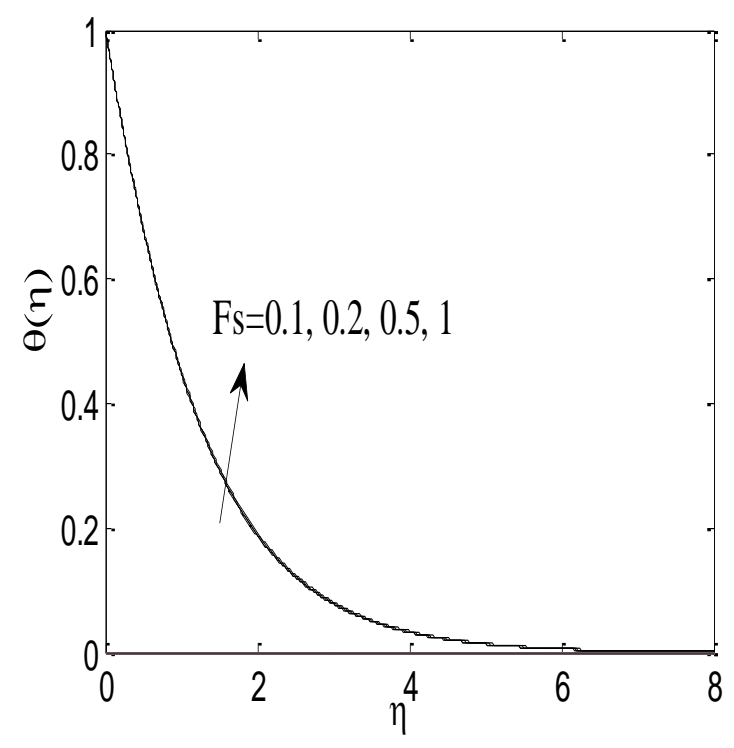

Fig. 6: Temperature profile for different values of $F S$

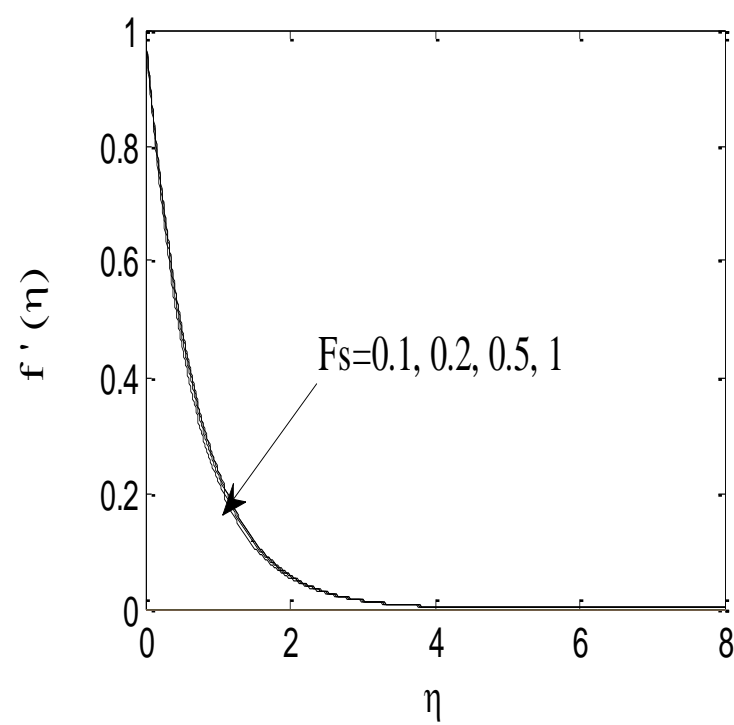

Fig. 5: Velocity profile $f^{\prime}(\eta)$ for different values of $F S$

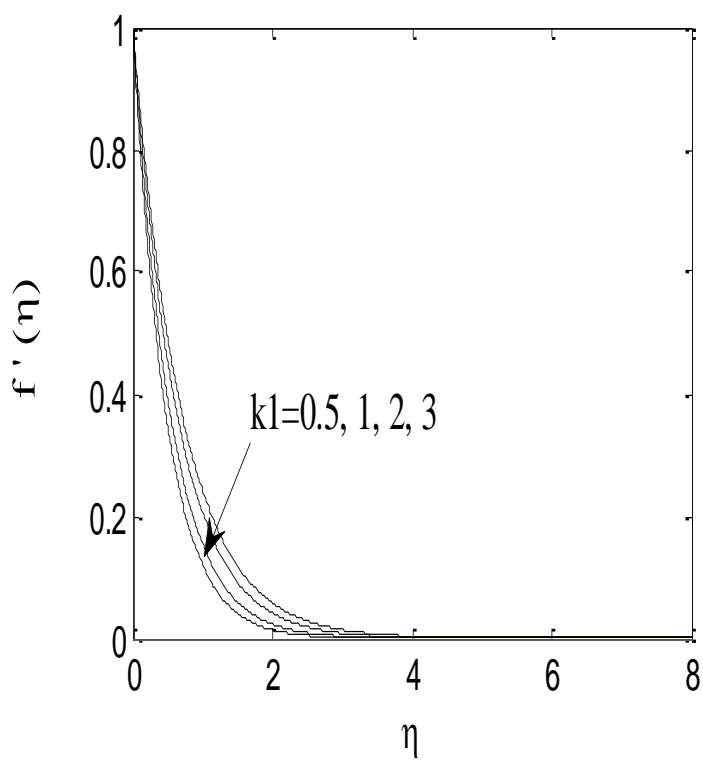

Fig.7: Velocity profile $f^{\prime}(\eta)$ for different values of $k_{1}$ 


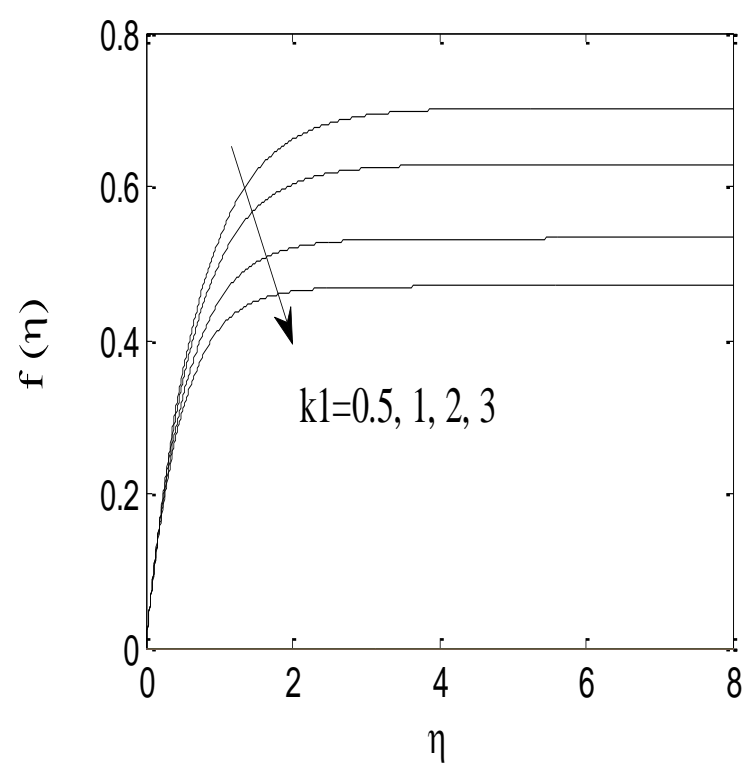

Fig.8: Velocity profile $f(\eta)$ for different values of $k_{1}$

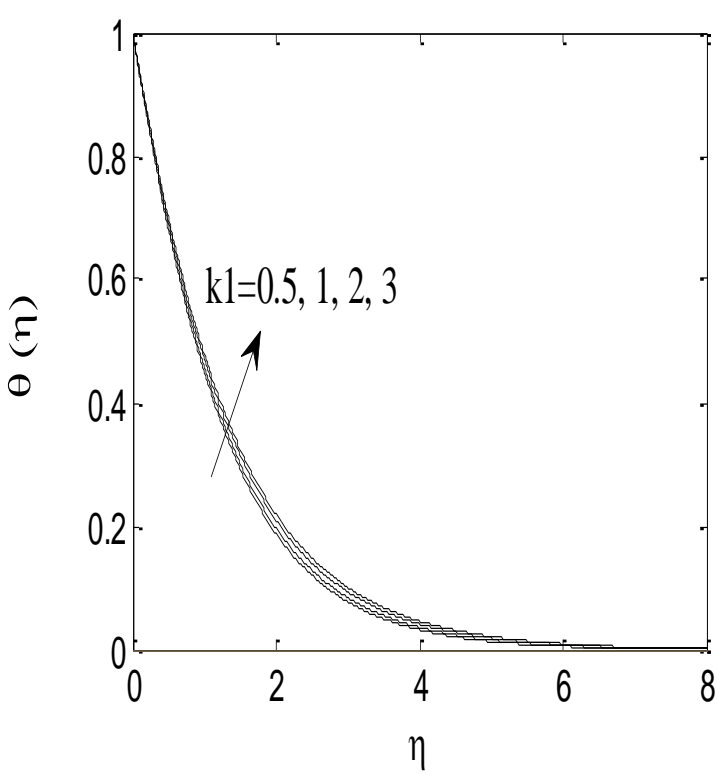

Fig. 9: Temperature profile for different values of $k_{1}$

Fig. 10 shows the effect of thermal stratification parameter $n$ on temperature profile $\theta(\eta)$. It is observed that the temperature decreases with an increase in the thermal stratification parameter. This is due to the fact that increase in thermal stratification parameter means increase in free stream temperature or decrease in surface temperature which results decrease in the thermal boundary layer thickness.

Fig. 11 reveals the effect of Prandtl number on temperature profile $\theta(\eta)$ respectively. It is shown that the temperature decreases with an increase in Prandtl number. As expected, viscous force increases and thermal diffusivity reduces with increase of Prandtl number. The influence of heat absorption/generation parameter on the temperature is plotted in Fig. 12. It is seen that temperature increased as the heat absorption/generation parameter increases.

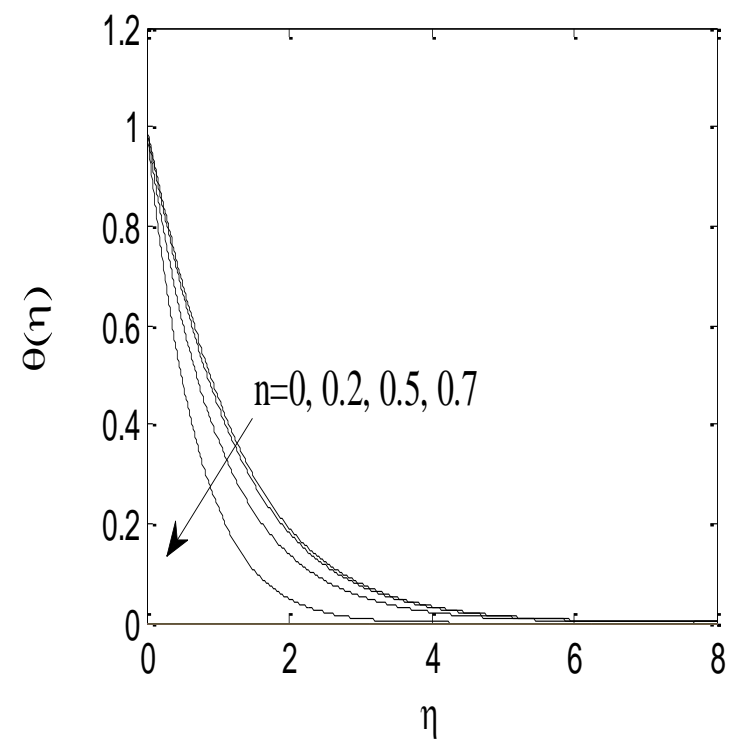

Fig.10 Temperature profile for different values of $n$

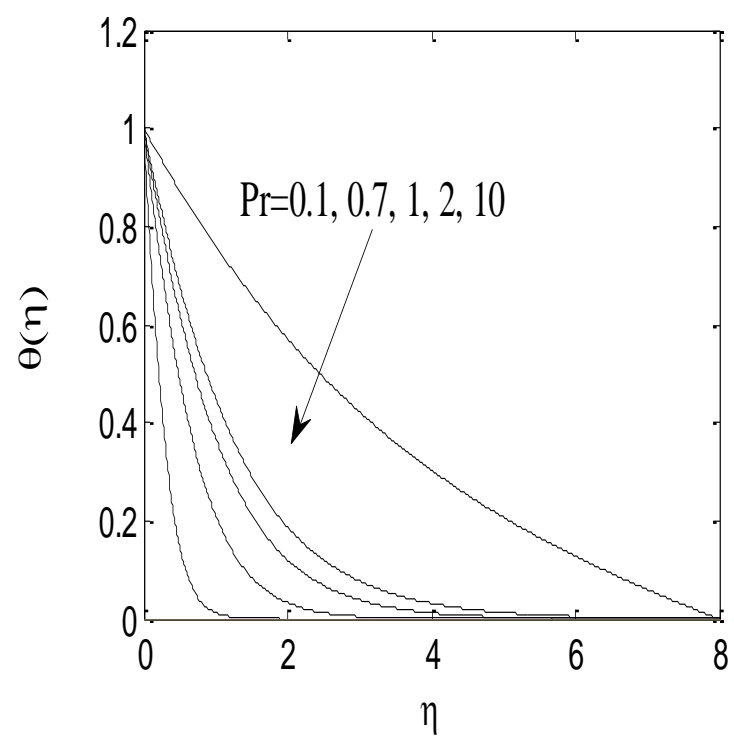

Fig.11 Temperature profile for different values of $\operatorname{Pr}$

Fig. 13 depicts the temperature profile $\theta(\eta)$ for different values of Eckert number. It is noticed that an increase in the Eckert number results an increase in the temperature profile. 


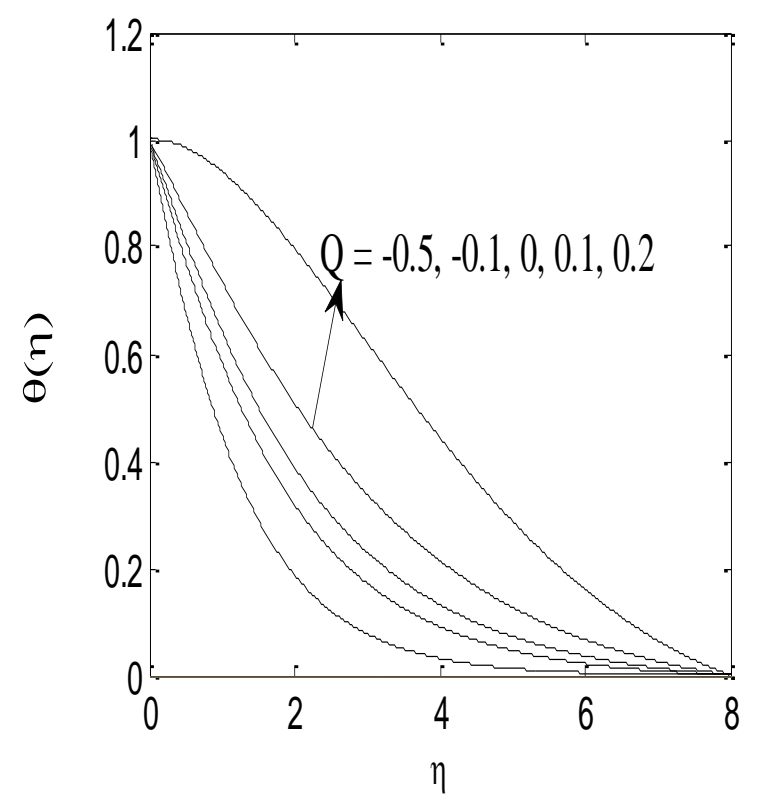

Fig. 12: Temperature profile for different values of $Q$

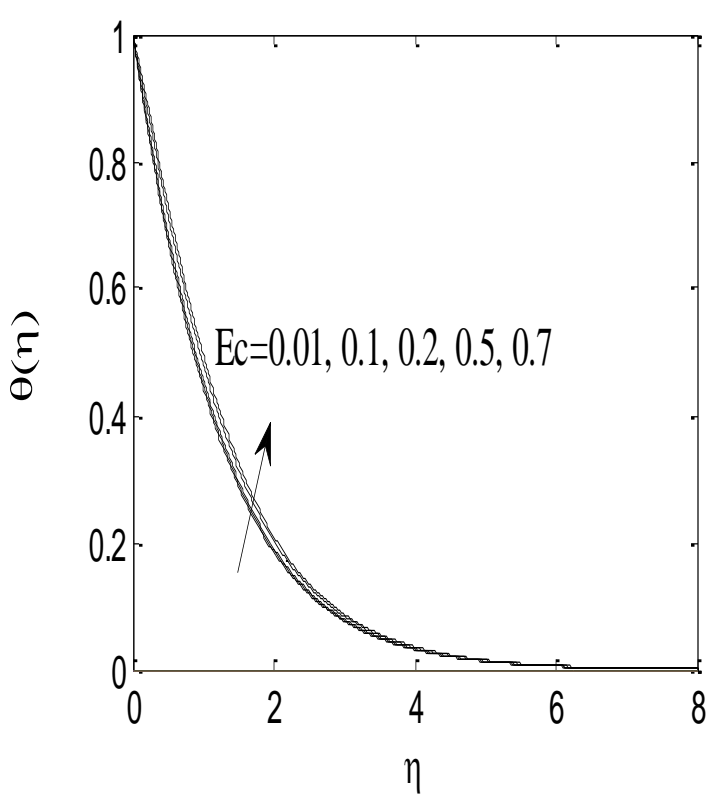

Fig. 13: Temperature profile for different values of $E c$

\section{Conclusion}

In this paper, an analysis for MHD non-Darcian flow due to stretching sheet embedded thermally stratified medium with viscous dissipation, heat source and thermal stratification is presented. The main finding of the present study is summarized as follows:

- As increasing the inertia, porous and magnetic parameters, reduced the velocity of fluid but enhanced the temperature.

- The higher values of the thermal stratification parameter result in lower temperature profile.

- The temperature of the fluid increases with increase in the values of Eckert number and heat generation/absorption parameter but decrease with an increase in Prandtl number.

The current study of thermal stratification effects on MHD non-Darcy flow over a horizontal stretching sheet embedded in a porous medium has wide industrial applications as well as in many branches of engineering.

\section{Reference}

Acharya, M., Singh, L. P. and Dash, G. C. (1999): Heat and mass transfer over an accelerating surface with heat source in the presence of suction and blowing, International Journal of Engineering Science, Vol. 37, pp. 189211. http://dx.doi.org/10.1016/S0020-7225(98)00064-0

Ahmed, S. (2010): Induced magnetic field with radiation fluid over a porous vertical plate: analytical study, Journal of Naval Architecture and Marine Engineering, Vol.7, pp.83-94. http://dx.doi.org/10.3329/jname. v7i2.5662

Animasaun, I.L. and Aluko, O.B. (2014): Analysis on variable fluid viscosity of non- Darcian flow over a moving vertical plate in a porous medium with suction and viscous dissipation, IOSR Journal of Engineering (IOSRJEN), Vol. 4, pp. 18-32. https://doi.org/10.9790/3021-04841832

Hooman, K. and Gurgeci, H. (2008): Effects of temperature dependent viscosity on Be'nard convection in a porous medium using a non-Darcy model, International Journal of Heat and Mass Transfer, Vol. 51, pp. 11391149. https://doi.org/10.1016/j.ijheatmasstransfer.2007.04.013 
Kandasamy, R. and Khamis, A. (2007): Thermal stratification effects on nonlinear hydromagnetic flow over a vertical stretching surface with a power-law velocity. International Journal of Applied Mechanics and Engineering, Vol.12, 47-54.

Madhu, J. V., Rajasekhar, M. N. and Reddy, B. S. (2015): Effects of viscous dissipation and thermal stratification on chemical reacting fluid flow over a vertical stretching surface with heat source, Advances in Applied Science Research, Vol. 6, No. 1, pp. 59-65.

Mohamed, R.A., Ibrahim, A. and Abo-Dahab, S.M. (2009): Finite element analysis of hydromagnetic flow and heat transfer of a heat generation fluid over a surface embedded in a non-Darcian porous medium in the presence of chemical reaction, Communications in Nonlinear Science and Numerical Simulation, Vol. 14, pp. 1385-1395. https://doi.org/10.1016/j.cnsns.2008.04.006

Mukhopadhyay, S., Mondal, I.C. and Reddy, R.S. (2012): Effects of thermal stratification on flow and heat transfer past a porous vertical stretching surface, Heat and Mass Transfer, Vol. 48, pp. 915-921.

https://doi.org/10.1007/s00231-011-0930-5

Nakayama, A. and Koyama, H. (1989): Similarity solutions for buoyancy-induced flows over a non-isothermal curved surface in a thermally stratified porous medium, Applied Sciences Research, Vol.46, pp. 309-332.

https://doi.org/10.1007/BF01998548

Pal, D. and Mondal, H. (2010): Effect of variable viscosity on MHD non-Darcy mixed convective heat transfer over a stretching sheet embedded in a porous medium with non- uniform heat source/sink, Communications in Nonlinear Science and Numerical Simulation, Vol. 15, pp. 1553-64. https://doi.org/10.1016/j.cnsns.2009.07.002

Pal, D. and Mondal, H. (2011): Effects of Soret-Dufour, chemical reaction and thermal radiation on MHD nonDarcy unsteady mixed convective heat and mass transfer over a stretching sheet, Communications in Nonlinear Science and Numerical Simulation, Vol. 16, pp. 1942-1958. https://doi.org/10.1016/j.cnsns.2010.08.033

Saha, S.C. and Hossain, M.A. (2004): Natural convection flow with combined buoyancy effects due to thermal and mass diffusion in a thermally stratified media, Nonlinear analysis: Modeling and Control, Vol. 9, pp. 89102.

Santhosh, D.K., Dass, A.K. and Anupam, D. (2009): Analysis of non-Darcy models for mixed convection in a porous cavity using a multigrid approach, Numerical Heat Transfer, Part A, Vol. 56, pp. 685-708.

https://doi.org/10.1080/10407780903424674

Singh, A.K. Agnihotri, P. and Singh, N.P. (2011): Transient and non-Darcian effects on natural convection flow in a vertical channel partially filled with porous medium: Analysis with Forchheimer-Brinkman extended Darcy model. International Journal of Heat and Mass Transfer, Vol. 54, pp. 1111-1120.

https://doi.org/10.1016/j.ijheatmasstransfer.2010.11.011

Singh, A.K., Kumar, R., Singh, U., Singh, N.P. and Singh, A.K. (2011): Unsteady hydromagnetic convective flow in a vertical channel using Darcy-Brinkman-Forchheimer extended model with heat generation/absorption: Analysis with asymmetric heating/cooling of the channel walls, International Journal of Heat and Mass Transfer, Vol. 54, pp. 5633-5642. https://doi.org/10.1016/j.ijheatmasstransfer.2011.06.009

Taklifi, A. and Aghanajafi, C. (2012): MHD non-Darcian flow through a non-isothermal vertical surface embedded in a porous medium with radiation, Meccanica, Vol. 47, pp. 929-937.

https://doi.org/10.1007/s 11012-011-9484-3 